\title{
Prevalensi Penyakit Tidak Menular pada Fasilitas Kesehatan Tingkat Pertama di Kota Bandung Tahun 2013-2015
}

\author{
Cindy Cahya Adhania', Guswan Wiwaha², Pandji Irani Fianza ${ }^{3}$ \\ ${ }^{1}$ Fakultas Kedokteran, Universitas Padjadjaran \\ ${ }^{2}$ Departemen Ilmu Kesehatan Masyarakat, Fakultas Kedokteran Universitas Padjadjaran \\ ${ }^{3}$ Departemen Ilmu Penyakit Dalam, Fakultas Kedokteran, Universitas Padjadjaran/ \\ Rumah Sakit Umum Pusat DR. Hasan Sadikin, Bandung
}

\begin{abstract}
Abstrak
Penyakit tidak menular (PTM) diprediksi akan meningkat. Di Indonesia, PTM mengalami baik peningkatan maupun penurunan. Adanya perbedaan antara prediksi dengan data dapat dikarenakan terbatasnya data terpublikasi sehingga kurang menggambarkan perkembangan terkini PTM. Untuk mengetahui lebih jauh mengenai perkembangan PTM di Indonesia, dibutuhkan data prevalensi PTM pada daerah tertentu, terutama di Kota Bandung. Tujuan penelitian yaitu mengetahui prevalensi PTM di Kota Bandung dan perkembangannya. Penelitian ini merupakan penelitian deskriptif observasional dengan desain studi potong lintang. Objek penelitian berupa laporan bulanan 1 (LB1) Sistem Pencatatan dan Pelaporan Puskesmas (SP3) Kota Bandung tahun 2013, 2014, dan 2015. Penelitian dilakukan di Kota Bandung pada Bulan Februari 2016-November 2016. Hasil menunjukan bahwa prevalensi PTM di Kota Bandung pada tahun 2013, 2014, dan 2015 secara berurutan yaitu 25,35\%, 23,21\%, dan 26,98\%. Kategori PTM yang meningkat diantaranya penyakit kelainan metabolik. Disimpulkan bahwa telah terjadi peningkatan prevalensi PTM di Kota Bandung dari tahun 2013 ke tahun 2015. Di masa mendatang, diperlukan data prevalensi PTM secara lebih menyeluruh dalam jangka waktu yang lebih lama untuk hasil yang lebih akurat.
\end{abstract}

Kata kunci : Bandung, fasilitas kesehatan tingkat pertama, penyakit tidak menular, prevalensi

\section{Prevalence of Noncommunicable Diseases at Primary Healthcare in Bandung City in 2013-2015}

\begin{abstract}
Non-communicable diseases (NCDs) were predicted to rise. In Indonesia, NCDs experienced both increase and decrease. The difference between the prediction and the data could be due to the limited availibility of published data so that may not illustrated the latest developments of NCDs. To learn more about the development of NCDs in Indonesia, prevalence data of NCDs in certain region, especially in Bandung City, was needed. This study aimed to determine the prevalence of NCDs in Bandung City and its development. The study was an observational descriptive, cross-sectional study. The object of the study was the monthly report 1 of registry and reporting system of community health center (Laporan Bulanan 1 (LB1) Sistem Pencatatan dan Pelaporan Puskesmas (SP3)) of Bandung City in 2013, 2014 and 2015. The study was conducted in Bandung city in February 2016-November 2016. The results were the prevalence of NCDs in Bandung City in 2013, 2014 and 2015 were $25,35 \%, 23,21 \%$ and 26,98\%, respectively. One of the disease categories that has increased was metabolic disorder. In conclusion, there is a rise in prevalence of NCDs in Bandung City from 2013 to 2015. In the future, a more comprehensive data of NCDs prevalence, in a longer period of time, is needed for a more accurate result.
\end{abstract}

Keywords : Bandung, noncommunicable diseases, prevalence, primary healthcare

Korespondensi:

Cindy Cahya Adhania

Fakultas Kedokteran, Universitas Padjadjaran

Jl. Prof. Dr. Eyckman No. 38 Bandung 40161

Mobile : 085691952943

Email : cindycahyaadhania@gmail.com 


\section{Pedahuluan}

Penyakit tidak menular (PTM) adalah penyakit atau kondisi medis yang tidak dapat ditularkan dari satu individu ke individu lainnya. Mayoritas PTM terjadi di negara berpendapatan rendah dan menengah. Berdasarkan data WHO, PTM merupakan penyebab dari 68\% kematian di dunia pada tahun 2012. Diprediksi, PTM akan terus meningkat. ${ }^{1}$ PTM merupakan tantangan dalam dunia kesehatan. ${ }^{2}$

Di Indonesia, menurut Survei Kesehatan Rumah Tangga (SKRT) 1995, SKRT 2001, dan Riset Kesehatan Dasar (RISKESDAS) 2007, persentase kematian disebabkan PTM secara berurutan adalah $41,7 \%$, 49,9\%, dan 59,5\%. Telah terjadi transisi proporsi penyebab kematian, dari sebelumnya lebih banyak kematian disebabkan penyakit menular, menjadi lebih banyak kematian disebabkan PTM. Selain itu, berdasarkan data Sistem Informasi Rumah Sakit (SIRS) tahun 2009-2010, persentase proporsi pasien PTM rawat inap meningkat $2,5 \%$ dan persentase proporsi pasien PTM rawat jalan meningkat 0,39\%. ${ }^{1}$ Sedangkan, menurut RISKESDAS 2013 , beberapa PTM tertentu mengalami kenaikan prevalensi, tetapi beberapa PTM tertentu lainnya mengalami penurunan. ${ }^{3}$ Adanya perbedaan antara prediksi dengan data dapat dikarenakan data yang terpublikasi hanya meliputi beberapa PTM terpilih pada periode tertentu, sehingga kurang dapat menggambarkan perkembangan terkini PTM. Untuk mengetahui lebih jauh mengenai perkembangan PTM di Indonesia, dibutuhkan data prevalensi PTM pada daerah tertentu, terutama di Kota Bandung. Penelitian ini bertujuan untuk mengetahui prevalensi PTM di Kota Bandung dan perkembangannya pada beberapa tahun terakhir.

\section{Metode}

Penelitian ini merupakan penelitian deskriptif observasional, dengan desain studi potong lintang, menggunakan metode total sampling dalam pemilihan sampel. Objek penelitian berupa laporan bulanan 1 (LB1) Sistem Pencatatan dan Pelaporan Puskesmas (SP3) Kota Bandung tahun 2013, 2014, dan 2015. LB 1 yang dimaksud meliputi data kesakitan penyakit dari 73 puskesmas yang terdapat di Kota Bandung. Data LB 1 diperoleh dari Dinas Kesehatan Kota Bandung dengan izin. Penelitian dilakukan di Kota Bandung pada Bulan Februari 2016 hingga November 2016. Kriteria inklusi adalah data LB1 SP3 Kota Bandung tahun 2013, 2014, dan 2015. Kriteria eksklusi adalah data kesakitan penyakit menular dan data kesakitan penyakit yang tidak terinci menular atau tidak menular, yang turut tergabung di dalam LB1 SP3.

PTM yang dimaksud dalam penelitian adalah penyakit yang tidak ditularkan dari satu individu ke individu lain dan tergolong ke dalam kategori PTM berdasarkan Peraturan Menteri Kesehatan (PERMENKES) Republik Indonesia nomor 71 tahun 2015 tentang penanggulangan penyakit tidak menular. Data penelitian diolah menggunakan rumus period prevalence yaitu $\frac{\text { Jumlah kasus baru + kasus lama }}{\text { Jumlah populasi beresiko }} 100 \%$ Populasi berisiko yang dimaksud dalam penelitian adalah pengunjung puskesmas Kota Bandung tahun 2013, 2014, dan 2015. Hasil pengolahan data disajikan dalam bentuk tabel dan grafik. Penelitian ini telah mendapatkan ethical clearance dari Komisi Etik Penelitian Kesehatan Fakultas Kedokteran Universitas Padjadjaran Bandung dengan nomor registrasi 0116060671.

\section{Hasil}

Ditemukan bahwa dari tahun 2013 hingga 2015, kategori penyakit sistem pembuluh darah menempati peringkat pertama, kategori penyakit sistem muskuloskeletal dan jaringan ikat menempati peringkat kedua, dan kategori penyakit kulit dan jaringan subkutan menempati peringkat ketiga. Kategori penyakit sistem pembuluh darah meliputi penyakit hipertensi primer, hipertensi sekunder, angina pektoris, infark miokard akut, penyakit jantung iskemik lainnya, emboli paru, penyakit gagal jantung, infark serebral, stroke, penyakit pembuluh darah lain non infeksi, hemoroid, hipotensi spesifik, dan penyakit serebrovaskular tidak spesifik. Kategori penyakit sistem muskuloskeletal dan jaringan ikat meliputi penyakit gout, artritis, nyeri punggung bawah, rematisme, myalgia, serta neuralgia dan neuritis. Kategori penyakit kulit dan jaringan subkutan meliputi penyakit dermatitis kontak dan eksema.

Pada tahun 2013 ditemukan prevalensi PTM di Kota Bandung sebesar 25,35\%. Prevalensi tertinggi ditempati kategori penyakit sistem pembuluh darah dengan angka 9,73\%. Berdasarkan profil kesehatan Kota Bandung, pada tahun 2013 tercatat 1.827 .199 kunjungan rawat jalan ke puskesmas Kota Bandung. Data lebih lengkap dapat dilihat pada tabel 1 .

Pada tahun 2014 ditemukan prevalensi PTM di Kota Bandung sebesar 23,21\%. Prevalensi tertinggi ditempati kategori penyakit sistem pembuluh darah dengan angka 8,97\%. Berdasarkan profil kesehatan Kota Bandung, 
pada tahun 2014 tercatat 1.879 .178 kunjungan rawat jalan ke puskesmas Kota Bandung. Data lebih lengkap dapat dilihat pada tabel 2.

Pada tahun 2015 ditemukan prevalensi PTM di Kota Bandung sebesar 26,98\%. Prevalensi tertinggi ditempati kategori penyakit sistem pembuluh darah dengan angka 10,41\%. Berdasarkan profil kesehatan Kota Bandung, pada tahun 2015 tercatat 1.799 .591 kunjungan rawat jalan ke puskesmas Kota Bandung. Data lebih lengkap dapat dilihat pada tabel 3.

Secara umum, terjadi penurunan prevalensi PTM sebesar 2,14\% dari tahun 2013 ke 2014, diikuti peningkatan sebesar $3,77 \%$ dari tahun 2014 ke 2015. Secara keseluruhan, telah terjadi peningkatan prevalensi sebesar 1,63\% dari tahun 2013 ke tahun 2015, seperti yang tertera pada gambar 1.

Tabel 1 Prevalensi PTM di Kota Bandung Tahun 2013

\begin{tabular}{|c|c|c|c|c|c|c|c|}
\hline \multirow[t]{2}{*}{ Peringkat } & \multirow[t]{2}{*}{ Kategori Penyakit } & \multicolumn{2}{|c|}{ Kasus Baru } & \multicolumn{2}{|c|}{ Total Kasus } & \multicolumn{2}{|c|}{$\begin{array}{l}\text { Period Prevalence } \\
\text { (total kasus } \div \\
\text { jumlah } \\
\text { pengunjung) }\end{array}$} \\
\hline & & $\mathbf{L}$ & $\mathbf{P}$ & $\mathbf{L}$ & $\mathbf{P}$ & $\mathbf{L}$ & $\mathbf{P}$ \\
\hline 1 & $\begin{array}{l}\text { Penyakit Sistem Pembuluh } \\
\text { Darah }\end{array}$ & 26711 & 48589 & 60712 & 117035 & $3,32 \%$ & $6,41 \%$ \\
\hline 2 & $\begin{array}{l}\text { Penyakit Sistem } \\
\text { Muskuloskeletal dan Jaringan } \\
\text { Ikat }\end{array}$ & 33989 & 68800 & 45234 & 108707 & $2,48 \%$ & $5,95 \%$ \\
\hline 3 & $\begin{array}{l}\text { Penyakit Kulit dan Jaringan } \\
\text { Subkutan }\end{array}$ & 11363 & 16032 & 13238 & 18948 & $0,72 \%$ & $1,04 \%$ \\
\hline 4 & $\begin{array}{l}\text { Penyakit Telinga dan Prosesus } \\
\text { Mastoideus }\end{array}$ & 12752 & 12757 & 14168 & 14362 & $0,78 \%$ & $0,79 \%$ \\
\hline 5 & $\begin{array}{l}\text { Penyakit Kelainan Endokrin, } \\
\text { Gizi dan Metabolik }\end{array}$ & 2908 & 5130 & 7857 & 14522 & $0,43 \%$ & $0,79 \%$ \\
\hline 6 & Penyakit Sistem Pernapasan & 3544 & 4423 & 5490 & 7014 & $0,30 \%$ & $0,38 \%$ \\
\hline 7 & Penyakit Susunan Saraf & 3444 & 7183 & 4050 & 7999 & $0,22 \%$ & $0,44 \%$ \\
\hline 8 & $\begin{array}{l}\text { Penyakit pada Mata dan } \\
\text { Adneksa }\end{array}$ & 2109 & 2755 & 2711 & 3709 & $0,15 \%$ & $0,20 \%$ \\
\hline 9 & Gangguan Jiwa dan Perilaku & 1224 & 1744 & 2834 & 3108 & $0,16 \%$ & $0,17 \%$ \\
\hline 10 & $\begin{array}{l}\text { Penyakit Sistem Saluran } \\
\text { Kemih dan Kelamin }\end{array}$ & 1364 & 2632 & 1963 & 3140 & $0,11 \%$ & $0,17 \%$ \\
\hline 11 & $\begin{array}{l}\text { Tumor Ganas/Neoplasma } \\
\text { Ganas }\end{array}$ & 795 & 1480 & 1163 & 2130 & $0,06 \%$ & $0,12 \%$ \\
\hline 12 & $\begin{array}{l}\text { Penyakit Darah dan Alat } \\
\text { Pembentuk Darah dan } \\
\text { Beberapa Kelainan yang } \\
\text { Berhubungan dengan } \\
\text { Mekanisme Kekebalan } \\
\text { (Imun) }\end{array}$ & 921 & 1729 & 1093 & 2070 & $0,06 \%$ & $0,11 \%$ \\
\hline & Jumlah & 88372 & 160497 & 146345 & 288382 & $8,01 \%$ & $15,78 \%$ \\
\hline
\end{tabular}


Tabel 2 Prevalensi PTM di Kota Bandung Tahun 2014

\begin{tabular}{|c|c|c|c|c|c|c|c|}
\hline \multirow[t]{2}{*}{ Peringkat } & \multirow[t]{2}{*}{ Kategori Penyakit } & \multicolumn{2}{|c|}{ Kasus Baru } & \multicolumn{2}{|c|}{ Total Kasus } & \multicolumn{2}{|c|}{$\begin{array}{c}\text { Period Prevalence } \\
\text { (total kasus } \div \\
\text { jumlah } \\
\text { pengunjung) }\end{array}$} \\
\hline & & $\mathbf{L}$ & $\mathbf{P}$ & $\mathbf{L}$ & $\mathbf{P}$ & $\mathbf{L}$ & $\mathbf{P}$ \\
\hline 1 & $\begin{array}{l}\text { Penyakit Sistem Pembuluh } \\
\text { Darah }\end{array}$ & 27230 & 48481 & 59061 & 109521 & $3,14 \%$ & $5,83 \%$ \\
\hline 2 & $\begin{array}{l}\text { Penyakit Sistem } \\
\text { Muskuloskeletal dan Jaringan } \\
\text { Ikat }\end{array}$ & 34911 & 67187 & 44978 & 87754 & $2,39 \%$ & $4,67 \%$ \\
\hline 3 & $\begin{array}{l}\text { Penyakit Kulit dan Jaringan } \\
\text { Subkutan }\end{array}$ & 10956 & 16002 & 12907 & 18970 & $0,69 \%$ & $1,01 \%$ \\
\hline 4 & $\begin{array}{l}\text { Penyakit Telinga dan Prosesus } \\
\text { Mastoideus }\end{array}$ & 10591 & 10972 & 12566 & 13523 & $0,67 \%$ & $0,72 \%$ \\
\hline 5 & $\begin{array}{l}\text { Penyakit Kelainan Endokrin, } \\
\text { Gizi dan Metabolik }\end{array}$ & 3599 & 5782 & 9220 & 15323 & $0,49 \%$ & $0,82 \%$ \\
\hline $6 *$ & Penyakit Susunan Saraf & 4432 & 6982 & 6186 & 10282 & $0,33 \%$ & $0,55 \%$ \\
\hline $7 \#$ & Penyakit Sistem Pernapasan & 3901 & 4576 & 5472 & 6911 & $0,29 \%$ & $0,37 \%$ \\
\hline 8 & $\begin{array}{l}\text { Penyakit pada Mata dan } \\
\text { Adneksa }\end{array}$ & 2748 & 3251 & 3621 & 4507 & $0,19 \%$ & $0,24 \%$ \\
\hline 9 & Gangguan Jiwa dan Perilaku & 1038 & 1175 & 2403 & 2747 & $0,13 \%$ & $0,15 \%$ \\
\hline 10 & $\begin{array}{l}\text { Penyakit Sistem Saluran } \\
\text { Kemih dan Kelamin }\end{array}$ & 1033 & 1853 & 1541 & 2257 & $0,08 \%$ & $0,12 \%$ \\
\hline 11 & $\begin{array}{l}\text { Tumor Ganas/Neoplasma } \\
\text { Ganas }\end{array}$ & 873 & 1556 & 1285 & 2298 & $0,07 \%$ & $0,12 \%$ \\
\hline 12 & $\begin{array}{l}\text { Penyakit Darah dan Alat } \\
\text { Pembentuk Darah dan } \\
\text { Beberapa Kelainan yang } \\
\text { Berhubungan dengan } \\
\text { Mekanisme Kekebalan } \\
\text { (Imun) }\end{array}$ & 1076 & 1537 & 1182 & 1722 & $0,06 \%$ & $0,09 \%$ \\
\hline & Jumlah & 102388 & 169354 & 160422 & 275815 & $8,54 \%$ & $14,68 \%$ \\
\hline
\end{tabular}

*Peringkat naik \#Peringkat turun

Tabel 3 Prevalensi PTM di Kota Bandung Tahun 2015

\begin{tabular}{|c|c|c|c|c|c|c|c|}
\hline \multirow[t]{2}{*}{ Peringkat } & \multirow[t]{2}{*}{ Kategori Penyakit } & \multicolumn{2}{|c|}{ Kasus Baru } & \multicolumn{2}{|c|}{ Total Kasus } & \multicolumn{2}{|c|}{$\begin{array}{l}\text { Period Prevalence } \\
\text { (total kasus } \div \\
\text { jumlah } \\
\text { pengunjung) }\end{array}$} \\
\hline & & $\mathbf{L}$ & $\mathbf{P}$ & $\mathbf{L}$ & $\mathbf{P}$ & $\mathbf{L}$ & $\mathbf{P}$ \\
\hline 1 & $\begin{array}{l}\text { Penyakit Sistem Pembuluh } \\
\text { Darah }\end{array}$ & 29874 & 54486 & 64374 & 122875 & $3,58 \%$ & $6,83 \%$ \\
\hline 2 & $\begin{array}{l}\text { Penyakit Sistem } \\
\text { Muskuloskeletal dan Jaringan } \\
\text { Ikat }\end{array}$ & 36717 & 80518 & 46326 & 99441 & $2,57 \%$ & $5,53 \%$ \\
\hline 3 & $\begin{array}{l}\text { Penyakit Kulit dan Jaringan } \\
\text { Subkutan }\end{array}$ & 13759 & 19720 & 14899 & 21770 & $0,83 \%$ & $1,21 \%$ \\
\hline $4 *$ & $\begin{array}{l}\text { Penyakit Kelainan Endokrin, } \\
\text { Gizi dan Metabolik }\end{array}$ & 4378 & 7692 & 11364 & 20764 & $0,63 \%$ & $1,15 \%$ \\
\hline
\end{tabular}




\begin{tabular}{|c|c|c|c|c|c|c|c|}
\hline $5 \#$ & $\begin{array}{l}\text { Penyakit Telinga dan Prosesus } \\
\text { Mastoideus }\end{array}$ & 9747 & 10203 & 11509 & 11938 & $0,64 \%$ & $0,66 \%$ \\
\hline 6 & Penyakit Susunan Saraf & 3984 & 7204 & 5327 & 9741 & $0,30 \%$ & $0,54 \%$ \\
\hline 7 & Penyakit Sistem Pernapasan & 4061 & 5372 & 5540 & 7618 & $0,31 \%$ & $0,42 \%$ \\
\hline 8 & $\begin{array}{l}\text { Penyakit pada Mata dan } \\
\text { Adneksa }\end{array}$ & 4206 & 5746 & 5225 & 7223 & $0,29 \%$ & $0,40 \%$ \\
\hline $9 *$ & $\begin{array}{l}\text { Penyakit Sistem Saluran } \\
\text { Kemih dan Kelamin }\end{array}$ & 1892 & 3043 & 2891 & 3508 & $0,16 \%$ & $0,19 \%$ \\
\hline $10^{*}$ & $\begin{array}{l}\text { Tumor Ganas/Neoplasma } \\
\text { Ganas }\end{array}$ & 1605 & 3161 & 2050 & 4269 & $0,11 \%$ & $0,24 \%$ \\
\hline $11 \#$ & Gangguan Jiwa dan Perilaku & 1140 & 1507 & 2082 & 2414 & $0,12 \%$ & $0,13 \%$ \\
\hline 12 & $\begin{array}{l}\text { Penyakit Darah dan Alat } \\
\text { Pembentuk Darah dan } \\
\text { Beberapa Kelainan yang } \\
\text { Berhubungan dengan } \\
\text { Mekanisme Kekebalan } \\
\text { (Imun) }\end{array}$ & 613 & 1434 & 706 & 1608 & $0,04 \%$ & $0,09 \%$ \\
\hline & Jumlah & 111976 & 200086 & 172293 & 313169 & $9,57 \%$ & $17,40 \%$ \\
\hline
\end{tabular}

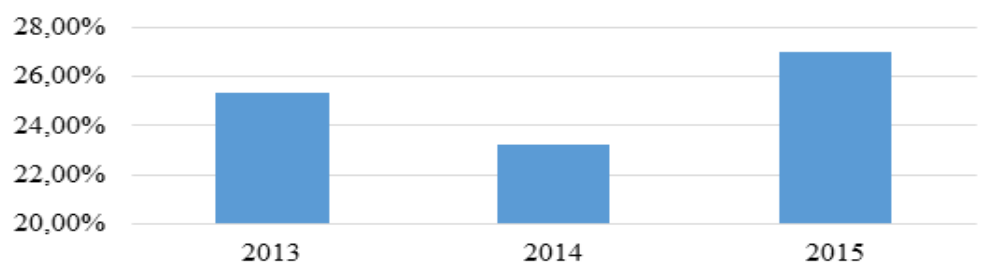

Gambar 1 Prevalensi PTM Tahun 2013-2015

\section{Pembahasan}

Meningkatnya PTM merupakan permasalahan kesehatan yang terjadi di berbagai negara, termasuk di area Asia Tenggara. ${ }^{4,5}$ Selain itu, PTM juga merupakan tantangan dalam aspek surveilans. ${ }^{6}$ Penelitian ini berfokus pada Kota Bandung, ibukota provinsi Jawa Barat, Indonesia. Pada penelitian ini, data yang dipergunakan adalah data kesakitan penyakit di puskesmas, yang didapat dari Dinas Kesehatan Kota Bandung. Dimana data kesakitan penyakit yang tersedia lengkap pada tingkat Dinas Kesehatan Kota Bandung adalah data kesakitan penyakit di puskesmas, sedangkan data kesakitan penyakit di rumah sakit tidak tersedia dengan lengkap. Data kesakitan di puskesmas tersebutlah yang dipergunakan dalam pembentukan profil kesehatan Kota Bandung, data tersebut dianggap representatif terhadap Kota Bandung. Penemuan bahwa adanya keterbatasan kelengkapan data PTM di tingkat dinas kesehatan kota ini menjadi catatan tersendiri yang mana perlu dikaji ulang kedepannya. Keterbatasan ketersediaan data ini dapat mempengaruhi gambaran keseluruhan dari kondisi PTM di Kota Bandung.

Dibandingkan dengan prevalensi PTM nasional pada RISKESDAS 2013, prevalensi PTM di Kota Bandung tahun 2013 didapati lebih rendah. Dapat diinterpretasikan, bahwa prevalensi PTM di Kota Bandung lebih rendah dari prevalensi PTM nasional. Selanjutnya pada tahun 2014, ditemukan adanya penurunan prevalensi PTM, yang mana berbeda dengan prediksi. Penemuan ini, dapat dipengaruhi oleh beberapa aspek. Jika ditelaah kembali, prediksi bahwa PTM akan terus meningkat didapat berdasarkan temuan adanya pola transisi penyakit menuju PTM. ${ }^{1}$ Kemungkinan, transisi tersebut terjadi bukan disebabkan oleh peningkatan jumlah PTM tetapi dikarenakan penurunan jumlah penyakit menular sehingga secara keseluruhan menunjukan kecenderungan peningkatan PTM. Juga, dapat dipengaruhi oleh pemilihan population at risk yang digunakan dalam penelitian ini, yaitu jumlah pengunjung puskesmas, yang mana mungkin kurang cocok sebagai pembagi dalam perhitungan prevalensi, dikarenakan tidak 
seperti jumlah penduduk yang dari tahun ke tahun cenderung konstan, jumlah pegunjung puskesmas dapat mengalami variasi yang cukup signifikan sehingga dapat mempengaruhi hasil akhir dari perhitungan prevalensi.

Berikutnya, ditemukan bahwa kategori penyakit dengan prevalensi tertinggi adalah kategori penyakit sistem pembuluh darah, diikuti oleh kategori penyakit sistem muskuloskeletal dan jaringan ikat di peringkat kedua. Kedua kategori penyakit tersebut memiliki prevalensi yang cenderung lebih tinggi dibandingkan dengan kategori penyakit pada peringkat ketiga dan seterusnya. Penyakit dengan jumlah kasus terbanyak pada kategori penyakit sistem pembuluh darah adalah hipertensi primer, sedangkan penyakit dengan jumlah kasus terbanyak pada kategori penyakit sistem muskuloskeletal dan jaringan ikat adalah myalgia. Secara keseluruhan, hipertensi merupakan penyakit dengan jumlah kasus terbanyak pada penelitian ini. Kedepannya, penyakit hipertensi memerlukan perhatian tersendiri dikarenakan kebanyakan kasus hipertensi tidak terkontrol dengan baik dan jumlahnya cenderung lebih tinggi di lapangan. ${ }^{7}$ Hipertensi dan beberapa PTM umum lainnya juga berdampak pada aspek ekonomi pasien secara signifikan. ${ }^{8}$

Pada penelitian ini, ditemukan adanya empat kategori PTM yang secara bertahap mengalami peningkatan dalam tiga tahun terakhir, yaitu kategori penyakit kelainan endokrin, gizi, dan metabolik, kategori penyakit pada mata dan adneksa, kategori penyakit sistem saluran kemih dan kelamin, serta kategori penyakit tumor/ neoplasma ganas. Kejadian PTM pada dasarnya terkait erat dengan empat faktor risiko utama PTM yaitu pola makan tidak sehat, kurang aktifitas fisik, konsumsi rokok, dan konsumsi alkohol, yang mana terus meningkat di berbagai kalangan masyarakat sekarang dan perlu ditanggulangi secara serius., ${ }^{9,10}$ Sedangkan, kategori PTM yang secara bertahap menurun dalam tiga tahun terakhir yaitu kategori penyakit telinga dan prosesus mastoideus, kategori penyakit gangguan jiwa dan perilaku, serta kategori penyakit darah dan alat pembentuk darah dan beberapa kelainan yang berhubungan dengan mekanisme kekebalan (imun). Dapat diartikan, ketiga kategori PTM tersebut sudah cukup terkendali sehingga dapat terjadi penurunan pada jumlah prevalensi.

Penyakit tidak menular lebih banyak ditemukan pada wanita dibandingkan pria. Wanita cenderung lebih rentan terhadap faktor risiko PTM dibanding pria. Diantaranya, sehubungan dengan faktor risiko pertama, yaitu pola makan tidak sehat, kasus obesitas lebih banyak ditemukan pada wanita. ${ }^{11,12}$ Lalu faktor risiko kedua, yaitu kurangnya aktifitas fisik, umum terjadi pada kaum wanita, dipengaruhi diantaranya oleh aspek sosial dan kultural yang cenderung tidak menuntut wanita untuk beraktifitas fisik. ${ }^{13,14}$ Faktor risiko ketiga yaitu konsumsi rokok, ditemukan bahwa jumlah perokok wanita cenderung meningkat. ${ }^{15,16}$ Pada faktor risiko keempat, yaitu konsumsi alkohol, didapati bahwa wanita cenderung lebih mudah terkena efek samping dari konsumsi alkohol pada dosis yang lebih rendah dibanding pria. ${ }^{17,18}$

Program pegendalian PTM secara global mengacu pada Global Action Plan For the Prevention and Control of Noncommunicable Disease dari WHO. Sedangkan, untuk acuan dalam proses implementasinya, WHO telah merancang Package of Essential Noncommunicable (PEN) Disease Interventions for Primary Health Care in Low-Resource Settings, dimana PEN bertumpu pada layanan kesehatan tingkat pertama serta mempertimbangkan fakta bahwa mayoritas PTM terjadi di negara berpendapatan rendah dan menengah yang memiliki keterbatasan masingmasing. Di Indonesia sendiri, Kementerian Kesehatan RI telah merancang "Pedoman Teknis Penyelenggaraan Pengendalian Penyakit Tidak Menular di Puskesmas", yang dirancang mengikuti arahan dari panduan WHO. Layanan kesehatan primer berperan penting dalam menguatkan usaha pengendalian PTM secara komperhensif, meliputi aspek preventif, promotif, kuratif, dan rehabilitatif.

Aspek preventif meliputi pencegahan primer, sekunder, dan tersier, yang secara umum bertujuan untuk meningkatkan pengetahuan dan kesadaran masyarakat akan PTM. Aspek promotif bertujuan membangun dan membina lingkungan masyarakat yang sehat, diantaranya dapat dilakukan dengan cara mempromosikan program kesehatan pemerintah seperti program pola hidup bersih sehat (PHBS), dan program CERDIK yang terdiri dari cek kesehatan secara rutin, enyahkan asap rokok, rajin aktifitas fisik, diet seimbang, istirahat cukup, dan kelola stres. Aspek kuratif meliputi kompetensi tenaga medis dalam melaksanakan tatalaksana PTM, dari penanganan faktor risiko PTM hingga penanganan PTM secara terintergrasi, termasuk dalam menangani kegawatdaruratan PTM dan merujuk. Aspek rehabilitatif meliputi kompetensi tenaga medis dalam menangani pasien PTM dengan turut mempertimbangkan aspek sosial, ekonomi, dan psikologis dengan tujuan mengurangi beban yang dirasakan pasien PTM, seperti diantaranya melaksanakan layanan homecare untuk pasien PTM yang dinilai membutuhkan. Dalam prakteknya, usaha pengendalian PTM di puskesmas turut dibantu 
oleh program kesehatan pemerintah seperti Program Pengelolaan Penyakit Kronis (Prolanis) yang diselenggarakan oleh Badan Penyelenggara Jaminan Kesehatan (BPJS). Prolanis ditujukan untuk peserta BPJS, bertujuan untuk menangani penyakit kronis dan meningkatkan kualitas hidup pasien penyakit kronis. Selain itu, puskesmas juga dibantu oleh fasilitas kesehatan lain seperti Pos Pembinaan Terpadu (Posbindu) PTM, yang berperan dalam pendeteksian dini dan monitoring PTM, beserta faktor risikonya.

Disisi lain, dalam Rencana Strategis (RENSTRA) Dinas Kesehatan Kota Bandung tahun 2013-2018, ditemukan bahwa belum dikeluarkannya target angka untuk prevalensi PTM pada indikator kinerja dari program/kegiatan pelayanan pencegahan dan penanggulangan PTM, sehingga tidak dapat dibandingkan antara hasil prevalensi yang didapat dengan indikator pengendalian PTM. Pengendalian PTM di Kota Bandung masih dalam tahap awal dan pengembangan, dimana fokus dari pengendalian PTM sekarang berupa peningkatan kualitas dan cakupan dari fasilitas pelayanan kesehatan, dimana layanan kesehatan berperan penting dalam pengendalian PTM. ${ }^{19,20}$

Keterbatasan dari penelitian ini adalah tidak meliputi data kesakitan dari penyakit yang tidak tercakup dalam LB1 SP3. Namun demikian, daftar penyakit yang terdata dalam LB1 sudah mencakup sebagian besar PTM. Kesimpulan dari penelitian ini adalah prevalensi PTM di Kota Bandung mengalami kenaikan dari tahun 2013 ke 2015. Serta, ditemukan adanya keterbatasan kesediaan data PTM di Kota Bandung, yang mana dapat mempengaruhi gambaran umum dari kondisi PTM di Kota Bandung. PTM merupakan tantangan kesehatan yang perlu ditanggapi serius di Kota Bandung. Program pengendalian PTM perlu dilaksanakan secara efektif dan berdedikasi, demi mencegah penurunan kualitas kesehatan masyarakat Kota Bandung. Maka dari itu, terbatasnya data kesakitan PTM di Kota Bandung perlu ditanggulangi. Di masa yang akan datang, diperlukan data prevalensi PTM secara lebih menyeluruh, dalam kurun waktu yang lebih lama, untuk memberikan hasil yang lebih akurat.

\section{Daftar Pustaka}

1. Kementerian Kesehatan Republik Indonesia. Data dan Informasi Kesehatan Penyakit Tidak Menular. 2012. Jakarta: Kementerian Kesehatan RI; 2012:48.

2. Remais J, Zeng G, Li G, Tian L, Engelgau M. Convergence of non-communicable and infectious diseases in low- and middle- income countries. International Journal of Epidemiology. 2012;42(1):221-227.

3. Riset Kesehatan Dasar. Laporan Nasional Riset Kesehatan Dasar 2013. 2013. Jakarta: Riset Kesehatan Dasar; 2013:304.

4. Dans A, Ng N, Varghese C, Tai E, Firestone $\mathrm{R}$, Bonita $\mathrm{R}$. The rise of chronic noncommunicablediseases in southeast Asia: time for action. The Lancet. 2011;377(9766):680689.

5. Dhillon P, Jeemon P, Arora N, Mathur $\mathrm{P}$, Maskey M, Sukirna R et al. Status of epidemiology in the WHO South-East Asia region: burden of disease, determinants of health and epidemiological research, workforce and training capacity. International Journal of Epidemiology. 2013;42(1):361362.

6. Kroll M, Phalkey R, Kraas F. Challenges to the surveillance of non-communicable diseases - a review of selected approaches. BMC Public Health. 2015;15(1):1-12.

7. Hussain M, Mamun A, Reid C, Huxley R. Prevalence, Awareness, Treatment and Control of Hypertension in Indonesian Adults Aged $\geq 40$ Years: Findings from the Indonesia Family Life Survey (IFLS). PLOS ONE. 2016;11(8):e0160922.

8. Finkelstein E, Chay J, Bajpai S. The Economic Burden of Self-Reported and Undiagnosed Cardiovascular Diseases and Diabetes on Indonesian Households. PLoS ONE. 2014;9(6):e99572.

9. Ahmed S, Hadi A, Razzaque A, Ashraf A, Juvekar S, Ng N et al. Clustering of chronic non-communicable disease risk factors among selected Asian populations: levels and determinants. Global Health Action. 2009;2(1):68-75.

10. Low W, Lee Y, Samy A. Non-communicable diseases in the Asia-Pacific region: Prevalence, risk factors and communitybased prevention. International Journal of Occupational Medicine and Environmental Health. 2014;28(1):20-26.

11. Christiani Y, Byles J, Tavener M, Dugdale P. Gender Inequalities in Noncommunicable Disease Risk Factors Among Indonesian Urban Population. Asia-Pacific Journal of Public Health. 2016;28(2):134-145.

12. Ng M, Fleming T, Robinson M, Thomson B, Graetz N, Margono C et al. Global, regional, and national prevalence of overweight and obesity in children and adults during 1980 2013: a systematic analysis for the Global Burden of Disease Study 2013. The Lancet. 2014;384(9945):766-781.

13. Ng N, Hakimi M, Van Minh H, Juvekar S, 
Razzaque A, Ashraf A et al. Prevalence of physical inactivity in nine rural INDEPTH Health and Demographic Surveillance Systems in five Asian countries. Global Health Action. 2009;2(1):44-53.

14. Nascimento T, Mussi F, Palmeira C, Santos C, Santos M. Factors related to leisure-time physical inactivity in obese women. Acta Paul Enferm. 2017;30(3):308-315.

15. Bonita R, Beaglehole R. Women and NCDs: Overcoming the neglect. Global Health Action. 2014;7(1):1-4.

16. Temmerman M, Khosla R, Laski L, Mathews Z, Say L. Women's health priorities and interventions. BMJ. 2015;351(1):h4147.

17. Sugarman D, DeMartini K, Carey K. Are Women at Greater Risk? An Examination of Alcohol-Related Consequences and Gender. American Journal on Addictions. 2009;18(3):194-197.
18. Wilsnack S, Wilsnack R, Kantor L. Focus on: Women and the Costs of Alcohol use. Alcohol Res. 2014;35(2):219-228.

19. Dinas Kesehatan Kota Bandung. Rencana Strategis Dinas Kesehatan Kota Bandung 2013-2018. 2014. Bandung: Dinas Kesehatan Kota Bandung; 2014:100-108.

20. Di Cesare M, Khang Y, Asaria P, Blakely T, Cowan M, Farzadfar F et al. Inequalities in non-communicable diseases and effective responses. The Lancet. 2013;381(9866):585597. 